\section{Armamento é Direitos Huma- nos: nossos fins, os meios e seus modos}

Recebido:

15.02.12

Aprovado:

06.11 .12

1. Professora adjunta da Universidade Candido Mendes, atua no

Programa de Mestrado em Direito.

E-mail:

jacquelinedeoliveira.muniz@gmail. com

2. Professor associado da Universidade Federal do Rio de Janeiro, atua no Programa de Engenharia de Produção e no Programa de Políticas Públicas, Estratégias de Desenvolvimento.

\begin{abstract}
The definition of the coercive capacity of the police is the condition of possibility for its political instrumentality as well as its governance. After a presentation that consolidates the theorization of the use of force for the production of consented obediences, the article presents three passages of foundational moments of modern police forces as illustrations of the alternative ways of defining that capability as examples of different ways of connecting ends and means, political preferences and weapons specifics. The issues that these bring about allow the presentation of two issues relevant to the brazilian debate on public security: the tension between universality and localism in the police instrument and the integral nature of ends and means in two instances which admit the possibility of the use of force - defense and public security.
\end{abstract} Keywords: Human Rights; Weapons Police, Governance, Public Security

\section{Introdução}

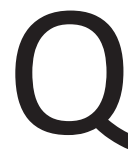

uerer não é poder. Queremos uma segurança pública que garanta os Direitos Humanos. Isso expressa nossos fins. Queremos mais: "políticas públicas de segurança pública", que os aproximem. Mas a expressão clara de fins e sua tradução nas metas de uma política são insuficientes. Seu des- 
tino é o de belas palavras no rumo do amargor mártir de se verem contraditas por um mundo imperfeito. Ponderar que "uma política tem que ser instrumentalizada" concede implicitamente a instrumentalização como algo distinto da política. E isso não basta. Uma política pública de Direitos Humanos e segurança precisa considerar, decidir e articular os fins com os meios que se propõe a usar, para que estes últimos não contradigam os primeiros e sejam os melhores para alcançá-los. A escolha politicamente guiada e tecnicamente embasada do armamento, dos meios e modos policiais, é a condição de possibilidade para uma política de segurança pública que se subordine aos Direitos Humanos.

Constrói-se a exposição da seguinte maneira: a primeira parte consolida a teorização sobre o uso de força para a produção de obediências consentidas, considerando o que é peculiar à segurança pública e às polícias: coercitividade. A segunda parte apresenta três passagens históricas, momentos fundacionais das polícias modernas. Ilustra algumas das diferentes formas de se conectar fins e meios, preferências políticas e especificidade de armamentos, na definição da capacidade coercitiva das polícias. As considerações finais usam dessas partes para exemplificar duas questões que parecem apropriadas para o Brasil: a tensão entre universalidade e localismo no instrumento policial, e a integralidade de fins e meios como percebidos em duas instâncias em que o uso de força pode ter lugar - a defesa e a segurança pública.

\section{Poder é Polícia}

Polícia existe para coagir. Coage pelo uso de força em ato ou em potência. Em ato, quando sujeita fisicamente, quando faz uso do cassetete, quando dispara uma pistola, um fuzil. Em potência, quando assinala presença e disposição para agir por um gesto; quando sopesa o cassetete, saca a pistola ou assesta o fuzil. Quando apenas se apresenta, armada e pronta, ou se sabe que pode se apresentar armada e pronta. Quando sopra um apito, pisca um farol ou aciona uma sirene; ou cumprimenta na rua. O uso de força policial é uma ação política da polis para impor a alguns o que destes se deseja que façam.

A capacidade coercitiva de uma polícia materializa as prioridades e escolhas de um determinado governo diante do estado da arte policial; decorre da política (policy) de Direitos Humanos e segurança no contexto do projeto político de um governo - central, provincial ou local, conforme os termos constitucionais e o desenho administrativo de um determinado Estado; busca compor escolhas de meios de força que possam atender às metas de Direitos Humanos e segurança, permitindo a ação bem sucedida da polícia de acordo com o que seja considerado desejável no uso de força policial. Um governo exige, tolera ou proíbe a 
posse de determinadas capacidades coercitivas, definidas e regradas em termos das circunstâncias (oportunidade) e formas (propriedade) de uso de força policial. Essa definição de capacidades é condição necessária para a governança da polícia. A conformidade da ação policial com os critérios de oportunidade e propriedade no uso de força circunscreve a responsabilização policial. Cada um desses elementos experimenta diferentes formas de pressão, adesão e resistência por parte dos diversos atores envolvidos no fazer da política pública. Esse fazer - da política de Direitos Humanos e segurança, da definição da capacidade coercitiva, da governança da polícia, dos termos da oportunidade e propriedade do uso de força, da responsabilização - admite variedade. Seja entre diferentes comunidades políticas (polities) ou governos, seja ao longo do tempo numa mesma comunidade política ou governo, expressando diferentes contextos sociais e prioridades políticas.

A decisão do governo de autorizar determinados armamentos e de alguns de seus modos de uso corresponde à sua proposta do que julga adequado ter como capacidade coercitiva da polícia; expressa um projeto de força para a polícia como instrumento da política de Direitos Humanos e segurança; faz estabelecer a polícia que melhor instrumentaliza de força a administração estatal para permitir uma distribuição consentida e seletiva de coercitividades que produza escassez de violências; concebe tal polícia em todos os detalhes relevantes, circunscrevendo os meios e modos que expressam tudo o que ela passa a ser capaz de fazer. Nesse processo, excluem-se famílias inteiras de alternativas, conformando-se as remanescentes às preferências de um determinado governo. Com isso, estabelecem-se os termos de responsabilização governamental e de accountability policial (LUSTGARTEN, 1986; PROENÇA JR., MUNIZ e PONCIONI, 2011). Isso significa que o governo precisa ser capaz de apreciar a especificidade e particularidade técnica, os requisitos, efeitos e consequências táticas das alternativas que compõem o projeto de força da polícia (CHANT, 1980; DUPUY, 1987; SUAREZ, 1998).

A escolha de uma determinada capacidade coercitiva tem que resolver o problema de quão capaz a polícia, enquanto organização, equipe ou agente individual, pode e deve ser. Trata-se de disponibilizar uma capacidade coercitiva que permita que a polícia seja suficiente, em termos estritos, suficientemente forte. Suficiente para ter expectativa razoável de sucesso quando o uso de força tiver lugar. Isso decorre de um juízo político de coercitividade adequada para uma resolução satisfatória de diversas situações em que o potencial ou concreto de força pode ser oportuno. Em termos instrumentais, isso corresponde aos diferentes resultados que se espera do uso apropriado de força diante da multiplicidade de manifestações individuais ou coletivas e de seu potencial de resistência à intervenção policial (QUIGLEY, 1983; O'CONNELL, 1990; GARNER, SCHADE e 
HEPBURN, 1996).

A delicadeza da questão é que forças policiais encontram-se submetidas a limites restritivos precisamente porque são policiais. Sua capacidade coercitiva é apenas a que o governo autoriza sob a chancela da sociedade policiada. Organização e agentes policiais estão sujeitos à responsabilização em termos da oportunidade e propriedade de uso da força, que excluem determinados armamentos e modos de uso de seu horizonte de ação.

Uma forma de resumir essa especificidade policial é dizer que se trata de um meio de força "comedido". Há situações em que se reconhece que a recalcitrância é mais forte do que o comedimento permite que a maior parte da polícia seja. A polícia, armada com cassetete, tem expectativa de superioridade contra a insubordinação e resistência de um indivíduo "genérico". A arma de fogo pode dar superioridade de força a um agente policial contra quem esteja desarmado. Mas isso não exaure as circunstâncias em que o uso de força policial pode ser oportuno, apenas aponta quando ele pode ser inapropriado porque não se tem expectativa razoável de sucesso.

Há um limiar aquém: mais policiais podem sobrepujar os oponentes, reunindo superioridade numérica. Mas isso não é certo. Dependendo das circunstâncias - por exemplo, um suspeito embarricado - tem-se que dispor de algum arranjo diferenciado de força. Este pode corresponder a alternativas de armamentos, de uso de armamento ou de métodos que não são os usuais, cuja propriedade só é admitida quando se está diante desse limiar. Isso pode corresponder a um rearmamento dos agentes policiais ("a escopeta na mala do carro", por exemplo) ou a equipes táticas especializadas (as assim chamadas "operações especiais policiais"). Mas mesmo isso admite outro limiar, a partir do qual as forças armadas podem ser a única alternativa de intervenção. Tem-se novamente um juízo político sobre as alternativas técnicas e táticas dessas forças combatentes, determinando o que se demandará destas em termos de responsabilização ao cumprirem uma missão policial (MUNIZ e PREONÇA JR., 2007).

Esses limiares são estruturais: existem porque a polícia é, e deve seguir sendo, comedida. A fração de ações policiais que estejam aquém ou além de cada um destes é contingente e circunstancial. Depende de especificidades locais e do que a população espera e demanda que o governo - seja em arranjos federativos, seja em unitários - possa fazer com a polícia diante de uma determinada situação (WILSON, 1968; BAYLEY, 1985).

Isso ressalta outro elemento estrutural. A polícia multiplica o seu efeito coercitivo pela crença compartilhada de que, se chamada, ela virá e, vindo, produzirá uma solução superior a dos meios privados e desiguais de força. A eficácia sim- 
bólica da "ideia de que existe polícia" modifica atitudes, produzindo coerção por um uso tão somente potencial de força (PROENÇA JR. e MUNIZ, 2006). Mas a sustentação dessa eficácia depende de sua funcionalidade em ato, no qual a sociedade testemunha e aprova o emprego da capacidade da polícia em resposta à sua chamada (BANTON, 1964; SKOLNICK, 1968 e 1975; BITTNER, 1974 e 1990; MUIR, 1977). Numa formulação clássica, esse efeito depende de que a sociedade reafirme constantemente o mandato policial, que considere a polícia seu instrumento de sanção, o "ou senão..." social diante do concreto ou potencial de transgressões ou violações às suas regras legais e legítimas do jogo (BITTNER, 1990, p. 9). A seu turno, isso depende de uma capacidade coercitiva que possibilite intervir quando "algo-que-não-devia-estar-acontecendo-está-acontecendo-e-alguém-devia-fazer-alguma-coisa-a-respeito-agora" (BITTNER, 1990, p. 249).

Isso permite identificar o mínimo da capacidade coercitiva numa dada sociedade, num dado contexto. Quem exerce o mandato policial tem que ser forte o suficiente para impor a solução policial nos termos em que a cidadania pactuada consente. A viabilidade molecular do mandato policial depende da quase certeza dessa avassaladora assimetria coercitiva (MUNIZ e PROENÇA JR., 2007), que assegura a conformação das atitudes dos cidadãos à solução policial autorizada (BAYLEY, 1994; SILVER, 2006).

Três Inícios: a "Nova Polícia" à moda de Inglaterra, a Gendarmerie do Continente e a Experimentação Policial nos EUA

Oferece-se uma sequência de ilustrações, estações no trajeto da história das polícias. São passagens em que a escolha do armamento como determinante da capacidade coercitiva politicamente desejada pode ser percebida de maneira nítida. Essa é uma forma de lidar com a "confusão conceitual" (misconceptualization). Ao se trazer ao texto uma ilustração, pode-se contornar o peso da justaposição de categorias de diferentes estruturas teóricas sem o lastro conceitual que as explica e poderia articulá-las em exposições comparadas (SARTORI, 1970). Tem-se, com isso, um mosaico expositivo pertinente porque remete aos momentos fundacionais das práticas policiais modernas, expondo suas raízes (NEWBURN, 2001). Distancia-se da perspectiva de imediata aplicabilidade que se põe sobre os estudos policiais (WALKER, 2004), reduzindo ainda o risco de cronocentrismo, da presunção da originalidade intrínseca do presente ao arrepio de consideração da História, que pode levar a um presentismo reflexivo e paralisante (ROCK, 2005).

Oferecem-se diversas "invenções" de "polícia". Fragmentos de história que, no seu plural, questionam a ambição autofundante e autossuficiente das teorias 
3. Quais sejam as modalidades de policiamento corresponde a uma discussão distinta das escolhas de seus meios e modos que as configuram. Mas há perspectivas de controle da polícia (PUNCH, 1983) e de administração da polícia (FYFE et al., 1995) que propõe a dominância ora de umas ora de outros na organização e gestão da ação policial. Aqui se enfatiza o papel diretivo de meios e modos no projeto de força das polícias diante das consequências de sua natureza instrumental; a discussão das modalidades de policiamento tem que aguardar outra ocasião.

4. Essa passagem histórica, como as demais, corresponde a uma destilação de diferentes fontes que compartilha uma síntese autoral focada no tema do artigo. O texto-chave dessa reconstrução é Klockars (1985), que articula os elementos apresentados na Parte 1 para discutir os casos britânicos e o dos EUA. Padfield (1979) e Lustgarten (1986) situam constitucionalmente, e Reith (1975), Radinowicz (1956), Critchley (1972), Inatieff (2006) e Emsley (1997) são fontes complementares do caso britânico. O detalhamento da complexidade do constable que se nativas; compartilham a singularidade do local no que se apresenta como universal nas narrativas sobre as, e das próprias, polícias; apontam para a polícia como produto de projetos políticos, projetos "de civis" e não "de policiais" (que ainda não existiam); retratam constructos situacionais, reflexos das transformações da cidadania, que encaminharam diferentes soluções para o desafio de sustentar a ordem pública e afirmar direitos diante da modernidade novecentista (DEVLIN, 1966; STYLES, 1987 e 2006; STRECHER, 1991; ZEDNER, 2006; RIGAKOS, MCMULLAN e JOHNSON, 2009); subsidiam o amadurecimento de uma "ciência social da polícia", que reconhece a sua especificidade como área de conhecimento, em contraste com uma "ciência social aplicada na polícia", restrita à replicação de abordagens ou resultados de outros objetos, que presume sua pertinência para o entendimento da polícia e dos policiamentos (BRODEUR, 2005; MANNING, 2005; MUNIZ e PAES-MACHADO, 2010).

Oferecem-se, portanto, ilustrações como convites para o pensar. O pensar sobre três formas - talvez mesmo, as três formas ${ }^{3}$ - de se produzir governo sobre as polícias: (i.) poder menos para fazer mais, da invenção da "Nova Polícia"; (ii.) poder mais para fazer menos, da adaptação de frações de tropas em polícias de Estados continentais europeus; e (iii.) a busca por proporcionalidade na capacidade de uso de força da polícia, da experimentação diversificada que marca a trajetória dos EUA.

\section{A "Nova Polícia" à moda de Inglaterra4: Poder menos para fazer mais}

A fundação da Polícia Metropolitana de Londres (“A Nova Polícia”), em 1829, expressou o aprendizado da democracia britânica acerca da importância de se governar os meios de força, contendo seu potencial de emancipação. Desde meados do Século XVIII, a guarda em rodízio por notáveis, as guardas de locais específicos, os caça-recompensas, os Bow Street Runners ("investigadores"), assim como os executores de ordens judiciais - todos remunerados pelos presos que apresentavam - haviam produzido uma sucessão de impasses na administração do policiamento e da justiça, revelando a inviabilidade de sua permanência.

Esses mecanismos locais, privados e ao mesmo tempo públicos, revelaram-se incapazes de lidar com a expectativa de direitos da cidadania britânica ou de garantir o governo de pessoas e território. Eram impotentes diante da anonimidade, do fluxo e do crescimento das populações urbanas. Existiam regiões sem lei, sobretudo na zona metropolitana de Londres, que havia crescido por sobre dezenas de vilas. A arbitrariedade, desvio e ineficácia das guardas privadas diante, por exemplo, de migrantes internos ou dos assaltantes de estradas produziu enorme insatisfação. Cada vez mais acusados eram trazidos às cortes e inocentados pelos júris, convictos de que estes haviam sido levados ao crime pelos 
caça-recompensas, que gozavam de imunidade. A "investigação" e a "execução da justiça" não gozavam de credibilidade porque seus operadores aceitavam ser pagos para não fazer, tanto quanto para fazer.

Isso culminou com uma sucessão de motins em Londres em meados dos 1820, em que foi necessário chamar o exército para restaurar a "Paz do Rei". Esse tipo de solução revelou-se um problema colossal para o Parlamento, porque depender das tropas do exército - a imagem dos canhões cercando o Parlamento para protegê-lo - era depender das tropas do exército. Foi o espectro do despotismo que levou ao processo de criação de algum arranjo de força que fosse claramente um não exército; claramente incapaz de oprimir o Parlamento; e, acima de tudo, claramente subordinado ao Parlamento (e não ao rei).

Essa não era uma questão simples. Uma força pervasiva para manter a ordem e fazer cumprir a lei podia servir de base para o mais forte partido político concebível. Afinal, o New Model Army do Parlamento havia sido capaz de derrotar o exército do rei e, depois, impor-se como governo por sobre o Parlamento no século XVII: o pesadelo dos canhões cercando o Parlamento para sujeitá-lo. A isso somava-se a clara percepção de que um arranjo desse tipo estaria sempre passível de apropriação privada. Em quaisquer mãos, poderia servir como um instrumento de tirania.

Para os britânicos, a noção de "polícia" tinha um sabor quase absolutista, do Ministére de la Police à moda de França, de Luíz XIV, ou, mais e pior ainda, de Bonaparte. Aqui a questão era a mesma - o risco de tirania. Mas havia outro aspecto. $\mathrm{O}$ que tal força podia e não podia fazer; como responsabilizá-la, como responsabilizar seus membros individualmente, pelo que fizessem ou deixassem de fazer; enfim, como governá-la.

Se a solução britânica nos parece extrema (como se verá a seguir), é porque não apreciamos o que à época significava "policiar". Na França, "policiar" gozava, sempre que oportuno, da completa imunidade de quem atuava em nome do Estado no que chamaríamos hoje de "polícia secreta". Tal distinção não existia; e esse era o ponto. A amplitude de tal imunidade foi capturada por Dumas, de "Os Três Mosqueteiros", no documento que o Cardeal Richelieu entrega à MiLady, sua agente, que protesta que, se fizer o que lhe é pedido, será condenada pela Lei do Rei. De posse do documento assinado por Richelieu, primeiro-ministro, que diz "o portador desta fez o que fez pelo bem da França", Milady tornou-se imune à lei, não importando o que fizesse. A mesma lógica, forma extrema da obediência devida, fazia os agentes policiais inimputáveis pelos crimes que viessem a cometer no curso de suas atividades.

A iniciativa decisiva da solução britânica, associada ao nome de Robert Peel, foi faz Bobby é devedor de Strecher (2006), Wade (2008) e Emsley (2009). 
uma mistura de imagens antigas e absoluta novidade material e organizacional: a "Nova Polícia". Tratou-se de uma força modesta em número, ao redor de mil, circunscrita ao território metropolitano de Londres, num raio inicial de sete miIhas (11 km), proibida de atuar no distrito dos prédios do Parlamento (a milha-quadrada da City, que teve sua própria polícia), respondendo por talvez meio milhão de pessoas; armada apenas com "cassetete que se pode ocultar sob as vestes" - e que se devia manter oculto sob estas. Consistiu numa organização pautada por responsabilidades e atos individuais, sem se fazer tropa. Esses eram atributos cruciais: uma força deliberadamente impedida de se constituir em unidade por si mesma, materialmente incapaz de lidar ou impor pela força contra uma tropa armada de fuzis e canhões; incapaz mesmo de prevalecer contra o público caso este se lançasse em massa contra ela.

Uma "Nova Polícia" que servisse para manter a paz e controlar a desordem, coibindo o crime, foi uma construção política traduzida de maneira sensível na divisa "a polícia é o público; o público, a polícia"; encarnava a concepção de obediência consentida, restrita a uma coerção autorizada e materialmente limitada - sem armamentos de corte ou de fogo. Isso não aconteceu de maneira fácil ou natural. Nem se sabia se tal força, "desarmada", poderia ser capaz de cumprir o que desta esperava-se.

A “Nova Polícia” expressou a ambição de afirmar uma coercitividade quotidiana, não apenas legal, mas, sobretudo, legítima. Para isso, contribuíram diversos fatores. O traje policial era um uniforme que emulava a roupa civil da baixa classe média de seu tempo, afirmando uma acessibilidade popular pela ausência dos signos de distinção da elite e pelo distanciamento do uniforme militar. Mas a disciplina pessoal dos policiais era feroz, inovadora, difícil: a face barbeada e o asseio, a alfabetização nas letras e nas quatro operações, os modos polidos, a imparcialidade cortês, a obrigatoriedade de atenção a qualquer demanda que Ihes fosse dirigida. Eram recorrentes em suas rondas regulares e sabidas, para verem e serem vistos, mas distantes até serem solicitados; passíveis de serem chamados, primeiro um, depois tantos quantos necessários atendendo ao apelo do som distintivo de seus apitos que se encontravam à venda para o público, que podia usá-los com o mesmo efeito mobilizador; agentes públicos restritos ao espaço público, mas ao alcance de qualquer um. Passar-se-iam décadas antes que a Nova Polícia pudesse sequer considerar entrar numa residência ou edificação privada sem ser convidada ou estar acompanhada por um oficial de justiça. Passar-se-iam décadas antes que se admitisse que a Nova Polícia pudesse lidar com mais que o presente imediato. Qualquer ideia de competência do detetive tinha mesmo que estar em mãos privadas, como Sherlock Holmes, porque tal intrusividade em mãos do Estado era o rumo da tirania da polícia secreta. 
Construir tal atitude em todos os policiais, instanciando-a como o modo de ser de uma organização tão dispersa e tão aberta ao contingente quanto a Nova Polícia foi uma obra monumental. A única vantagem foi a disponibilidade de um conjunto de veteranos que havia passado pelas guerras (a polícia feminina ainda aguardaria quase um século). A ênfase da seleção e aproveitamento dessa vivência estava nos que não haviam permanecido como tropa - tropa que formava soldados submissos, obedientes e quase mecânicos. Foram os cabos e sargentos que mais interessaram à Nova Polícia. Suas iniciativa, hábito de responsabilização e adaptabilidade construíram dispositivos tácitos de "autodisciplina", dos quais a Nova Polícia veio a depender. Mesmo assim, uma cifra pode dizer muito do empenho dos fundadores, da dificuldade da tarefa, e da demanda de continuidade dos esforços de inventar um meio de força comedido, a polícia à moda de Inglaterra: nos primeiros dois anos, $400 \%$ do efetivo autorizado passaram pela força. Os que não se adaptaram ao modo de ser policial que se desejava foram sumariamente demitidos, sem direito a retorno.

Assim, construiu-se a principal expectativa contemporânea do dever-ser "polícia". Uma expectativa em que a polícia é "civil", claro, ambiciosamente, convivencial, polida, mas "onipresente" e ao alcance de um apito. Claramente, nunca, jamais, uma força armada; uma polícia do público, administrada pelo Estado. Para nomear esse invento sem precedentes, num modo tão britânico de lidar com a novidade, adotou-se um termo medieval: constable (o vigia da vila).

Aqui se pode encerrar com dois elementos dessa forma peculiar de polícia que foi, e em larga medida ainda é, a "Nova Polícia". Por um lado, o mandato de cada constable é constitucional e direto do Parlamento. Ele deve deferência e obediência a seus superiores, exceto no que diz respeito à decisão de usar a força, pois a responsabilidade é pessoal. Não se tem obediência devida no que seja o ato policial do constable, que responde pessoalmente, individualmente, pelo que faça e deixe de fazer por decisão discricionária. A Nova Polícia era, e em larga medida segue sendo, uma criatura do Parlamento e não da Coroa. Ainda que mantenha a "Paz da Rainha", ela não é "royal", ela é controlada pelo Parlamento por meio do Home Office.

Por outro lado, o público tinha suas próprias ideias. Sabia claramente que os policiais não eram os constables que conheciam. Chamava-os de bobbies, os homens do homem forte Robert (Bob) Peel, parlamentar que presidia a "reforma da justiça", ou de peelers (descascadores, um trocadilho) porque certamente queriam ganhar algum. Foi um trabalho de anos edificar o bobby contra a suspeita e resistência popular à sua presença e modos de atuação, mas que acabou por instituir o "Robertinho", imagem de um dos atributos que, meio século mais tarde, mesmo a língua ferina de Oscar Wilde, com uma ponta de ironia, admitia ser "um dos motivos de inveja do mundo civilizado" na era Vitoriana: uma polí- 
5. Ainda que a inspiração dessa exposição seja o panorama de Mosse (1975), o texto-chave da destilação é Liang (1992), a quem Emsley e Weingberger (1991) e Rikagos, McMullan e Johnson (2009) somam substância para delinear um conjunto abrangente. Angolia e Taylor (2005, 2009) cobrem em amplitude e detaIhe "as Alemanhas". Besson (1982), Euloge (1985) e Anderson (2011) dão conta do caso francês e seus desdobramentos para o exterior. Estes são detalhados por Emsley (1999), que dá conta da disseminação e resistência à solução francesa na Europa, e Figurelli (2010), que assinala as distinções e escolhas dos casos britânico, francês e italiano. cia idônea para "servir e proteger".

A perspectiva de menos para mais na Nova Polícia correspondeu à construção política de uma força que tinha o comedimento como princípio, fabricando um imaginário no qual o uso de força sob consentimento dar-se-ia a convite; uma polícia com traje e maneirismos "civis", "desarmada", "provocada", "a serviço do público e não do Estado", cuja fórmula tinha seu avatar na fleuma cortês do bobby. Essa solução britânica serviu de fiel para a reconsideração dos diversos arranjos continentais europeus: algo como "nossa, que ideia boa - mas prefiro assim".

\section{Gendarmeries do Continentes: Poder mais para fazer menos}

Cada país, por vezes cada parte de um dos países europeus, tinha seus próprios arranjos para o uso da força, com distintos enquadramentos para policiamentos públicos ou estatais. Seu ajuste diante do que a Nova Polícia propunha consolidou-se em organizações de força capazes de mais para fazer menos.

Essa solução correspondeu à adaptação de uma parte dos exércitos para cumprir a tarefa que a Nova Polícia caracterizava como policial, sem perder esse efetivo no caso de uma guerra. Diferentemente das ilhas britânicas, esses Estados tinham fronteiras terrestres em disputa, vivendo uma dinâmica política de paz entre guerras, em que era imprudente fazer o contingente policial incapaz de combater. A isso, somaram-se os efeitos da tensão entre a especificidade histórica de cada região no uso da força para fins domésticos e a passagem napoleônica que exportou, impôs ou levou a uma oposição deliberada ao modelo francês da gendarmerie.

Nesse contexto, as forças policiais continentais serviam a dois senhores: aos fins da soberania sobre a população, a tarefa policial doméstica, e aos fins da soberania sobre o território, a tarefa combatente internacional. Isso explica sua diversidade de organização e de nomes. Em alguns casos, forças combatentes propriamente ditas separadas do exército; em outros, subordinadas tanto à pasta "da guerra" quanto da justiça ou dos assuntos domésticos; noutros casos ainda, sementes de novas formulações das práticas policiais de antes da "Nova Polícia". Nomeadas gendarmerie desde a própria França até a Rússia; ou por termos neutros, como a Guarda Nacional Republicana, de Portugal, ou ainda em termos opostos à sua natureza, como a Guardia Civil espanhola. Outros contextos políticos locais tomaram a ideia da gendarmerie de diversas formas e com diferentes ênfases: as Polizei diferenciadas das províncias das Alemanhas, as armas do Exército com responsabilidades "policiais" de paz na Holanda, ou no Império Austro-Húngaro, as Poli(s)(z)(ia) ao redor do Báltico. Em todos os casos, 
forças paramilitares para a sustentação da ordem e respaldo da lei, com ou sem a obrigação de "servir" à população, com ou sem um papel combatente externo, mas sempre como "tropas internas" de duplo propósito - policial ou combatente conforme as circunstâncias.

A conjugação dessa dupla atribuição política impôs o armamento longo, o fuzil ou a carabina, muito mais do que o controle da população - na maioria dos casos, desarmada - exigiria, mas que correspondia ao mínimo para poder compor-se como tropa para o combate. Lidar com essa enorme capacidade coercitiva no controle da população civil exigiu uma determinada qualificação adicional, expressa na fórmula dos Carabinieri: saber atirar com precisão suficiente, considerando o alcance e letalidade da carabina, mesmo montado a cavalo, para responsabilizar-se individualmente pelo uso do armamento.

Assim, construíram-se arranjos policiais de força capazes do "mais", porém destinados a fazer o "menos", com uma construção constante, cotidiana, do "menos" que se deveria e do mais que só excepcionalmente se poderia fazer. Nesses arranjos, a polícia é "militar", claro, disponível em seus quartéis e postos, de onde lança suas patrulhas que fazem rondas; formal, respondendo com presteza e obediência devida, autorizada a intervir quando achar que deve, sem esperar nem precisar de convite. Trata-se de o Estado nas ruas, nas esquinas e nas casas - sempre que as razões de segurança o exigirem. Consiste em uma polícia do Estado para controlar tanto quanto para atender o público (esse, o maior efeito da Nova Polícia), que adotou o comedimento como recurso, construindo um imaginário no qual o uso de força, com alguma medida de consentimento, seria pronto e tempestivo. É uma tropa que se faz polícia em traje "militar" e maneirismos "marciais", "armada (com armamento de guerra)", "intervencionista", "força do Estado pelo bem de todos", cuja fórmula tinha seu avatar na imagem, no brasão, da corporação, maior que seus membros.

\section{A Experimentação Policial nos Estados Unidos da América ${ }^{6}$ : a busca por propor- cionalidade na capacidade de uso de força}

Os EUA descobriram-se desconfortáveis entre essas duas alternativas. Na ausência de fronteiras terrestres que lhes obrigassem a lidar com a questão da soberania em seu primeiro meio século de existência, desejavam uma polícia minimalista e estritamente civil, que não poderia ser desarmada diante de uma população armada. O país não aceitava uma polícia do Estado que, no entanto, era uma necessidade para que a ação policial pudesse ter expectativa de sucesso diante da recalcitrância.

A vasta gama de alternativas dos EUA, ao longo de sua história e no contexto de seus arranjos federativos, expressa continuadas propostas de como resolver
6. Klockars (1985) é

o texto-chave para os Estados Unidos da América, para o qual também contribuem Wadman e Allison (1992), Miller (1999) e Gaines, Kappeler e Vaughn (1999). Doyle (2000) dá conta da exclusão do uso do exército para fazer cumprir a lei. A ampliação da capacidade coercitiva das polícias tem exemplificação para Boston, em Lane (1967), e mais amplamente em Monkkonen (2004). Costello (1972) e Miller (1999) relatam as idas e vindas do armamento policial autorizado das diversas polícias sobrepostas de Nova lorque. A realidade de fora dos grandes centros tendia a ser idiossincrática, como em Webb (1965) para os Texas Rangers, ou Harring e McMullin (1992), para a polícia de Buffalo. A singularidade dos United States Marshals tem sua melhor expressão em Calhoun (1991) e Victor (2004), com o detalhe sendo devedor de Bopp e Shultz (1972), Ball (1978) e Tefertiller (1999). 
esse dilema. Houve, e ainda há, sucessivas experimentações e adaptações, por um lado, diante do papel do armamento da população como instrumento de soberania; por outro, diante da dinâmica de constituição da soberania sobre população e território - que se pode associar à substituição de "the United States are" de seus primeiros cem anos para "the United States is".

A constituição dos EUA expressava uma viva consciência do risco de tirania de um New Model Army, de qualquer força armada permanente de grandes dimensões. A solução dos EUA teve suas raízes no processo revolucionário de sua independência. A população tinha o direito e praticava em larga escala a posse de armamentos de todos os tipos. Esse era um requisito tácito de cidadania em diversos Estados: estados, unidades federativas, mas essa letra maiúscula lembra que, nos primeiros cem anos, eles eram os detentores formais da soberania, sendo os Estados Unidos uma associação livre entre eles, daí "the United States are".

O povo armado, constituído em milícias, era o esteio de sua capacidade combatente. Os EUA logo ficaram mais fortes que quaisquer de seus vizinhos terrestres ao longo do século XIX, diante dos quais a mobilização das milícias estaduais era vista como - e foi - suficiente. As forças nacionais (federais) correspondiam apenas ao mínimo necessário para dotar de competência um corpo de oficiais e atender às necessidades mais imediatas e frugais de defesa. Desde cedo, foram proibidas de atuar na ordem doméstica, sendo restritas à guarnição de pontos fortes e arsenais.

O povo armado, agremiado nas comunidades, era o respaldo da lei e o mantenedor da paz. Essa realidade admitia diversas formas de policiamento, tanto privadas quanto públicas, não estatais e estatais, sendo estas últimas em sua origem eletivas, direta ou indiretamente, e com mandatos limitados tanto ad nutum quanto passíveis de expansão ad hoc. Cada county (um pequeno município, ao redor de uma única vila), tinha o seu sheriff, que muitas vezes era a única autoridade executiva. Este possuía um mandato fixo, ainda que sujeito à demissão sumária, com poder para contratar auxiliares (deputies), que traziam seus próprios armamentos ou os recebiam pelo county. O sheriff podia "jurar temporariamente" cidadãos voluntários como deputies, formando um grupo armado (uma posse) para dar conta de uma situação excepcional.

No início, a única força nacional doméstica era os United States Marshals, criada durante o período revolucionário por Washington e instituída sob a autoridade do Judiciário para proteger e fazer cumprir as decisões das cortes federais. 0 marshal de cada distrito judicial era designado por termo fixo de mandato de quatro anos, com poderes análogos aos de um sheriff, mas com autoridade para determinar a participação de cidadãos em posses. 
O marshal não era nem um law officer, nem um peace officer (BANTON, 1964). Era, antes, um ator político, um factotum, um cargo na carreira política, que instrumentalizava, com respaldo armado, decisões legais do Presidente, do Congresso ou das Cortes Federais. Não era nem civil, nem militar, mas algo distinto. Tinha um papel interno amplo, desde o serviço às cortes, passando pelo censo, a coleta de impostos e como porta-voz da Presidência ou do Congresso. Era de fato o único representante do governo da União, na maior parte do território, e seu agente nas fronteiras. Mas, com tudo isso, não dispunha de qualquer estrutura organizacional. Dependia de redes tácitas, de adjacência, com outros marshals, em regimes mais ou menos cooperativos. Mas podia comandar todos os recursos federais, inclusive o exército, quando encarregado de (re)estabelecer a ordem jurídica nacional.

Essas perspectivas foram dinamizadas pelas realidades cambiantes da fronteira interna do Oeste e dos grandes centros urbanos do Leste. Isso produziu uma enorme variedade de arranjos, ora civis e eleitos - em que o emprego policial era uma prenda do jogo político, como em Nova lorque; ora militares, estaduais - em que um corpo público de tropa armada oferecia-se aos counties, como os rangers do Texas. Com a abertura das fronteiras do Oeste mais distante (o far west - do Rio Mississipi ao Oceano Pacífico), teve-se o exercício do projeto dos EUA. Diante de nativos americanos não incorporados, que resistiam ou ameaçavam os colonos, usava-se o exército como força de invasão e ocupação. Diante de nativos americanos ou quaisquer outros incorporados aos EUA, os antigos colonos dos territórios de Ohio, Luisiana, Texas e dos territórios conquistados do México tinham a extensão da cidadania e do regime de sheriffs e marshals, ou do que mais se dispusesse em termos de reconhecimento legal de igualdade para com os demais concidadãos. Em todo esse processo, a dinâmica interna era pautada pela intenção de que a soberania era estadual ou mesmo, em diversos aspectos, do county: novamente, the United States are.

A Guerra Civil redefiniu esses termos ao tornar indissolúveis os vínculos entre os estados, pela instituição da primazia do governo nacional. Daí em diante, a perspectiva de federalização, isto é, de que o executivo federal tinha a prerrogativa de subordinar os assuntos internos dos estados reconstituiu a autoimagem dos Estados Unidos. The United States is, a unidade que continha uma diversidade de alternativas, expressas no pluralismo das práticas de policiamento.

Em termos dos arranjos de força para o policiamento público estatal, essa unidade admitia a continuidade dos arranjos locais e estaduais com um número crescente de agências federais que os complementavam e suplementavam - e, sempre que oportuno, podiam subordiná-los. O dilema inicial entre a solução desarmada britânica e a gendarmerie resolveu-se; seguiu, melhor dizendo, sendo resolvida pela subordinação estrita à comunidade, nos termos de comedi- 
mento que ela preferisse, admitindo o armamento que assegurasse uma proporcionalidade da capacidade policial diante da cidadania armada.

A questão passou a ser o quanto era "suficiente" para assegurar o sucesso da polícia diante da recalcitrância. Isso construiu um imaginário no qual o uso de força sob consentimento seguiria o que fosse a preferência de cada comunidade, variando ao longo do tempo, em ondas reformistas e modas sucessivas de profissionalização, cooptação privada, militarização. Tantas polícias quanto fossem os gostos dos pagadores de impostos, cuja vontade expressa-se por meio de seus representantes eleitos, admitindo alternativas organizacionais, procedimentais, de vestimenta, atitude, postura e armamento - mesmo contraditórias entre si, ou momentaneamente em desacordo com a comunidade. Trata-se de uma ideia de polícia como "representante do Povo", cujo avatar é o Police Officer; para quem ser policial, é um job.

\section{Consideração Finais}

As ilustrações foram necessárias para expor o que só o seu contraste permite: a diversidade das diferentes maneiras de se ter polícia (e, implicitamente, fazer polícia), diante do fato e das consequências de que "polícia é poder". Então, pode-se oferecer, como fechamento, um preâmbulo e duas considerações pertinentes à problemática da segurança pública no Brasil.

O preâmbulo pode ser feito por um exercício de empatia com o passado. No presente, como em cada um desses momentos históricos acima relatados, sabemos os nossos fins, os fins desejados de cada sociedade em face da política de Direitos Humanos e segurança. No presente, diferente de cada um desses momentos, deixamos em aberto a instrumentalidade da polícia que desejamos. Há diversas maneiras de se refletir sobre isso como forma de se participar do debate no Brasil.

Hoje, a centralidade da discussão brasileira pode ser dita finalista (MUNIZ e ZACCHI, 2005): quais os resultados que esta ou aquela política de Direitos Humanos e segurança produz, e portanto, qual política produz mais resultados (ADORNO, 1999; CANO, 2006; SAPORI, 2006; SOARES, 2007; ZALUAR, 2007; cf. BENGOCHEA, 2004; PONCIONI, 2005; ANDRADE, 2010; NÓBREGA JR., 2010). A natureza da questão faz com que seja admissível e necessária alguma forma de sistematização dos resultados. É oportuno que se tenha como coligir a multiplicidade e o volume das instâncias relevantes para a descrição e avaliação dos resultados para apreciar uma dada política de Direitos Humanos e segurança. Daí todo o cuidado e controvérsia ao redor de estatísticas, com tudo o que estas podem admitir de viés e manipulação, com tudo o que estas podem ofertar de abran- 
gência e rigor (NJAINE, 1997; LIMA, 2005; CERQUEIRA, 2010). As realidades do exercício do mandato policial questionam o primado de tal leitura agregada, quantitativamente anônima. Eventos individuais, ocasiões particulares em que a qualidade do exercício do mandato policial é trazida aos olhos da sociedade, podem ter considerável significado e influência nos resultados agregados. Daí todo o cuidado e controvérsia ao redor de seu relato, com tudo o que este pode admitir de espetacularização ou propaganda - seja na banalização do excepcional, seja na reificação de casos triviais como exemplares -, com tudo o que a apreciação qualitativa de eventos pode revelar em termos de significado, detalhe e descoberta (SILVA, 2007; PORTO, 2009). Mas mesmo com tais cautelas, algo se perde quando tudo o que se enxerga é a relação biunívoca entre uma dada política e um determinado conjunto de resultados; nossos fins, os meios e os seus modos.

Na defesa nacional, mas não na segurança pública, a discussão substantiva dos meios (e modos) para atender os fins da política põe-se de maneira inescapável. A busca dos fins pela guerra está indissoluvelmente associada a uma escolha explícita dos meios a serem utilizados, detalhando seus modos de uso. A busca dos fins pela segurança pública, que explicam a polícia, carece dessa clareza. Para a guerra, a decisão sobre os meios (e modos) é claramente uma decisão de governo. Um governo que não decida sobre os meios, ou que decida sobre meios sem a adequada densidade técnica, consciente do que diferentes meios permitem ou implicam na busca dos fins, tem explicações a dar a seus eleitores (GRAY, 1999; NIELSEN, 2001). Na segurança pública brasileira, a decisão sobre os meios tem-se apresentado como uma tarefa dos próprios meios, os policiais (PROENÇA JR., MUNIZ e PONCIONI, 2011).

Isso soa curiosamente paradoxal. Na defesa, na qual se admite o máximo de força e de intensidade de uso de força, em que o limite da disponibilidade de força é o das possibilidades logísticas, tem-se consciência de que a escolha dos meios é integral à alternativa coercitiva, e que o seu uso tem que ser controlado e submetido para que não contradiga os fins. Na segurança pública, na qual a força é por definição "comedida", conformada por critérios de legalidade e legitimidade, em que o que é autorizado remove capacidades inadequadas ou intoleráveis para uma dada preferência política, a aparência de tecnicalidade cria a situação em que tudo se passa como se só existisse uma alternativa, a alternativa técnica policial para além da decisão política, como se essa alternativa fosse intrinsecamente satisfatória. Esse é o preço que se paga no Brasil pela definição "puramente" técnica dos meios policiais. Esse é o preço de se agir como se o estado da arte policial contivesse as considerações políticas em si mesmo. E basta assim dizê-lo para que se avivem as experiências e reflexões de cada um para perceber que isso não é assim. Nem pode ser assim, pois a política atravessa to- 
das as dimensões do uso de força. Na guerra ou nos policiamentos, em missões de guerra, de paz ou policiais (PROENÇA JR., 2003), qualquer uso de força para coagir é política armada. Política levada adiante, numa formulação clássica, com o acréscimo de outros meios, os meios de força (CLAUSEWITZ 1984, p. 87).

A construção de uma universalidade da polícia, a ideia de que existiria uma "policialidade" comum a todas as formas de produção de obediências sob consentimento, tem diversas fontes. Sim, "polícia à moda de Inglaterra" ofereceu uma gama de possibilidades de resultados, meios (e modos) que repercutiram diferenciadamente em democracias (e fora de democracias). Dito de outra maneira, há uma dimensão generalizável da "solução policial" britânica para o problema da coercitividade em sociedades livres e plurais. Mas, desde o primeiro momento, tanto dentro da Grã-Bretanha (cuja peculiaridade, por exemplo, de Dublin em relação a Londres não está na ilustração), quanto no continente e depois nos EUA, essa "policialidade" universal foi instanciada de diversas formas. Mesmo apenas com os momentos que se relataram mais acima, já se pode apreciar o quão substancialmente distantes da "moda de Inglaterra" eles foram.

Diversas outras formas de se afirmar a universalidade do ser ou fazer policial têm dimensões entremeadas, análogas às que redundam da prática de um mesmo ofício - o "ser policial" em Xangai, em Londres, em Nova lorque ou no Rio. Estas expressam vinculações identitárias entre policiais, partilham algum aprendizado com experiências e reflexões, e podem ser objetos de marketing de um "mercado mundial de produtos policiais", que se apresenta como um cardápio do estado da arte - desde armamentos até propostas de políticas de segurança ou de programas policiais. Mais amplamente, tem-se um imaginário translocal de estórias e ficções policiais, que se nutre da experimentação do como lidar com e inibir transgressões, produzindo justiça. "Sherlock Holmes" ou "o policial que rompe as normas para fazer justiça contra tudo e todos (como o Capitão Nascimento)" são personagens, quase arquétipos, que habitam o nosso senso comum.

Em franco contraste com a substância e a aparência de tal "policialidade", universal, tem-se um extremo do localismo, que impõe que cada polícia seja ajustada à sua comunidade política (polity). Não poderia ser diferente: a polícia expressa o consentimento (mesmo que implícito) da polity, que a autoriza. Mas os fins, meios e modos da polícia tem que ser aceitáveis pela sociedade. O que seja o grau de tal aceitabilidade, ou mais estritamente, o quão abrangente esse ajuste acaba sendo, é, ele mesmo, uma questão local.

Ilustrar alguns dos momentos fundacionais das polícias modernas serviu como uma maneira de avivar essa criticalidade do localismo, explicitando seu papel nas invenções "da polícia" em cada caso. A clareza desse cerne localista, intrín- 
seco à viabilidade de qualquer arranjo policial, sugere que isso seja assim em todos os momentos, em todas as polícias, o tempo todo. As polícias são refundadas a cada governo, a cada nova política de Direitos Humanos e segurança. Essa refundação é ela mesma contingente, idiossincrática, conflituosa, expressão das prioridades políticas num determinado momento e das realidades sociais que essas prioridades buscam atender. Em termos mais amplos, tem-se uma (re) negociação política do consentimento público para policiar, a vivificação dos termos concretos do mandato policial administrado pelo Estado. Em termos mais estritos, há mudanças de maior ou menor escala, objeto de adesão ou resistência interna ou externa às organizações policiais. O projeto de força das polícias, a determinação de sua capacidade coercitiva, é parte do processo de comunicação, de direção de quem confere o mandato policial. Ele exige a integralidade de fins e meios porque só assim se pode aproximar o que se deseja da maneira que se deseja. Que se possa ter uma polícia desarmada em Londres - porque se está numa ilha, com uma população desarmada. Que se tenham polícia-de-fuzil-ou-carabina no continente - porque se pode ter que lutar como um exército. Que se possa ter tudo o que se deseje nos EUA - porque poder ter tudo que se queira, inclusive armamento para a população, é mais importante do que outras considerações. Exatamente por isso, admite-se uma medida substancial de continuidade entre os sucessivos projetos de força de polícia de uma dada polity. Tais escolhas de administração da obediência consentida só ficam inteligíveis em termos situados. Situados em termos materiais de insularidade ou armamento da população. Situados em termos do sistema de representações e práticas sociais de cada comunidade política. Que a polícia britânica seja fleumática e cortês, expressando mais a sua "britanicidade" vitoriana do que a sua "policialidade" universal.

Querer não é poder. A ambição de se sustentar os Direitos Humanos, razão de ser do provimento da segurança pública, não se esgota nem se cumpre pela enunciação de tal finalidade. Sua afirmação e extensão a toda a cidadania vai mais além do que a prescrição dos fins ou a enunciação de metas que possam aproximá-los; exige pactuação política para a construção de sua instrumentalidade, sobretudo naquelas dimensões em que se tem a expectativa de ter que impor sanções a violações desses direitos como parte da administração democrática da ordem pública; demanda a definição das ferramentas coercitivas que podem ser necessárias para sua afirmação. Nossos fins realizam-se pelos meios que consentimos e com os modos que autorizamos - resultado do jogo político que se resolve pela imposição da visão da maioria ou pela coalizão de diferentes posições. Sem tal integralidade, arriscamo-nos a que as finalidades sirvam tão somente para justificar os meios, qualquer um, e emancipar os modos, quaisquer destes. Armamentos são meios invasivos. São coisas que imobilizam, cortam, ferem pessoas, valores e direitos. Mas, por detrás dos armamentos, há 
direitos, valores e pessoas que delimitam quais armamentos a polícia pode ter, quais as ocasiões e modos de seu uso; para que seu poder, seja, esteja e mantenha-se comedido, orientado pelos nossos fins consentidos nos momentos e maneiras que determinamos, pois a escolha do armamento é Direitos Humanos.

Referências Bibliográficas

ADORNO, Sérgio. "Insegurança versus Direitos Humanos: entre a lei e a ordem". Tempo Social, Vol. XI, n. 2, 1999, p. 129-153.

ANDERSON, M. In Thrall to Political Change: Police and Gendarmerie in France. USA: Oxford University Press, 2011.

ANDRADE, V. F. de. Direito: Do direito fundamental à segurança pública: análise crítica do sistema constitucional de segurança pública brasileiro. Tese de Doutorado, PUC-SP, 2010.

ANGOLIA, J. R.; TAYLOR, H. Uniforms, Organizations \& History of the German Police. Vol. 1. R. James Bender, 2005.

ANGOLIA, J. R.; TAYLOR, H. Uniforms, Organizations \& History of the German Police, Vol. 2. R. James Bender, 2009.

BANTON, Michael. The Policeman in the Community. Basic Books, 1964.

BAYLEY, D. H. Patterns of Policing: A Comparative International Perspective. New Haven: Rutdgers University Press, 1985.

BAYLEY, David H. Police for the Future. New York and Oxford: Oxford University Press, 1994.

Ball, L. D. The United States Marshals of New Mexico and Arizona Territories, 1846-1912. University of New Mexico Press, 1978.

BENGOCHEA, J. L. P. et al. "A transição de uma polícia de controle para uma polícia cidadã". São Paulo em Perspectiva, vol. XVIII, 2004, no 1, p. 119-131.

BESSON, Richer. La Gendarmerie nationale. Editions X, 1982.

BITTNER, Egon "Florence Nightingale in pursuit of Willie Sutton: a theory of the police". In Bittner E. Aspects of Police Work. Boston, Mass: Northeastern University Press, 1990.

BITTNER, E. "Introduction”. In Bittner, E. Aspects of Police Work. Boston: Northeastern University Press, 1990. 
BOPP, W. ; SCHUTZ, D. A Short History of American Law Enforcement. Springfield: Charles Thomas, 1972.

BRODEUR, J-P. “Police Studies Past and Present". Police Quarterly, vol. VIII, n. 1, 2005, p. 44-56.

CALHOUN, F. S. The Lawmen: United States Marshals and Their Deputies 17891989. Penguin, 1991.

CANO, I. "Políticas de segurança pública no Brasil: tentativas de modernização e democratização versus a guerra contra o crime". Sur, Revista Internacional de Direitos Humanos, vol. III, n. 5, 2006, p. 136-155.

CERQUEIRA, D. R. C. Economia: Causas e consequências do crime no Brasil. Tese de Doutorado, PUC-RJ, 2010.

CHANT, C. How weapons work. Marshall Cavendish Ltd., 1980.

CLAUSEWITZ, C. On War. In Howard, M.; Paret, P. (eds.) Princeton: Princeton University Press, 1984.

COSTEllo, A. E. Our Police Protectors: History of the New York Police. 3rd ed. Patterson Smith, 1972.

CRITCHLEY, T. A. A History of Police in England and Wales. 2a Ed. Montclair, N.J.: Patterson Smith, 1972.

DEVLIN, J. Daniel. Police Procedure, Administration and Organization. Butterworths, 1966.

DOYLE, C. The Posse Comitatus Act and Related Matters: the use of the military to execute civilian law. Washington: Congressional Research Service, 2000.

DUPUY, T. N. Understanding War: history and theory of combat. New York: Paragon, 1987.

EMSLEY, C. The English Police: A Political and Social History. 2a Ed. Longman Group United Kingdom, 1997.

EMSLEY, C. Gendarmes and the State in Nineteenth-Century Europe. EUA: Oxford University Press, 1999.

EMSLEY, C. The Great British Bobby. Quercus, 2009.

EMSLEY, C.; WeINBerger, B. (eds.). Policing Western Europe: Politics, Professionalism, and Public Order, 1850-1940. Greenwood Press, 1991. 
EULOGE, G. Histoire de la police et de la gendarmerie: Des origines a 1940. Plon, 1985.

FIGURELLI, F. I Carabinieri Reali Dal 1814 Al 1895: Confronto Fra La Gendarmeria Francese, II Constabulary Inglese E II Corpo Dei Carabinieri Reali. Nabu Press, 2010.

FYFE, J. et al. Police Administration. 5a ed. McGraw-Hill, 1996.

GAINES, L.; Kappeler, V.; Vaughn, J. Policing in America. Cincinnati: Anderson, 1999.

GARNER, J., BUCHANON, J., SCHADE, T.; HEPBURN, J. Understanding the Use of Force By and Against Police. Washington DC: NIJ, 1996.

GRAY, C. "Clausewitz Rules, OK? The Future Is the past: With GPS". Review of International Studies, vol. XXV, 1999, p. 161-182.

HARRING, S. L.; MCMULLIN, L. M. "The Buffalo Police 1832-1900". In McCormick, K.; Visano, L. (eds.) Understanding Policing. Toronto: Canadian Scholar's Press, 1992.

IGNATIEFF, M. "2. Police and people: the birth of Mr. Peel's 'blue locusts"”. In T. Newburn (ed.). Policing: Key Readings. Willan Publishing (UK), 2006.

KLOCKARS, Carl B. The Idea of Police. Sage Publications Inc, 1985.

LANE, R. Policing the City: Boston, 1822-1885. EUA: Harvard University Press, 1967.

LIANG, H. The Rise of Modern Police and the European State System from Metternich to the Second World War. Cambridge University Press, 1992.

LIMA, R. S. Sociologia: Contando crime e criminosos em São Paulo: uma sociologia das estatísticas produzidas e utilizadas entre 1871 e 2000. Tese de Doutorado, USP, 2005.

LUSTGARTEN, L. The Governance of Police. London: Sweet \& Maxwell, 1986.

MANNING, Peter K. "The Study of Policing". Police Quarterly, vol. VIII, n. 1, 1985, p. 23-43.

MILLER, W. R. Cops and Bobbies: police authority in New York and London. 2a ed. EUA: Ohio State University Press, 1999.

MONKKONEN, E. H. Police in Urban America, 1860-1920. Cambridge University Press, 2004. 
MOSSE, G. L. (ed.). Police Forces in History. SAGE Publications, 1975.

MUIR Jr, W. K. Police: Streetcorner politicians. Chicago: The University of Chicago Press, 1977.

MUNIZ, J.; PAES-MACHADO, E. "Polícia para quem precisa de polícia: contribuições aos estudos de policiamento". Caderno CRH, vol. XXIII, n. 60, 2010, p. 437447.

MUNIZ, J.; PROENÇA Jr., D. “Da Accountability Seletiva à Plena Responsabilidade Policial”. In CARUSO, H. J. M; BLANCO, A. C. C. (orgs.) Polícia, Estado e Sociedade: Práticas de Saberes Latino-Americanos. Rio de Janeiro: PUBLIT, 2007.

MUNIZ, J.; ZACCHI, J. M. "Avanços, Frustrações e Desafios para uma Política Progressista, Democrática e Efetiva de Segurança Pública no Brasil". In ESCOBAR, Santiago (org.). Seguridad Ciudadana: concepciones y políticas. Caracas: Nueva Sociedad, 2005.

NEWBURN, T. "Commodification of policing in the late modern city". Urban Studies, vol. XXXVIII, N. 5-6, 2001, p. 829-48.

NIELSEN, S. Political Control Over the Use of Force: A Clausewitzian Perspective. Carlisle Barracks, PA: Strategic Studies Institute, Army War College, 2001.

NJAINE, K. et al. "A produção da (des)informação sobre violência: análise de uma prática discriminatória". Cadernos de Saúde Pública, vol XIII, N. 3, 1997, p. 405414.

NÓBREGA Jr., J. M. P. “A militarização da segurança pública: um entrave para a democracia brasileira". Revista de Sociologia e Política, vol. XVIII, n. 35, 2010, p. 119-130.

O'CONNELL, R. L. Of Arms and Men: A History of War, Weapons, and Aggression. New York: Oxford University Press, USA, 1990.

PADFIELD, C. F. British Constitution: made simple. WH Allen, 1979.

PONCIONI, P. "O modelo policial profissional e a formação profissional do futuro policial nas academias de polícia do Estado do Rio de Janeiro". Sociedade \& Estado, vol. XX, n. 3, 2005, p. 585-610.

PORTO, M. S. G. "Mídia, segurança pública e representações sociais". Tempo Social, vol. XXI, n. 2, 2009, p. 211-233.

PROENÇA Jr, D. “Enquadramento das Missões de Paz nas Teorias da Guerra e de Polícia”, in Paulo Luiz Moreaux Lavigne Esteves (org.) Instituições Internacionais: 
segurança, comércio e integração, pp. 246-290. Belo Horizonte: Pucminas, 2003. PROENÇA Jr., D.; MUNIZ, J. “'Stop or I'll call the Police!' The Idea of Police, or the effects of police encounters over time". British Journal of Criminology, vol. XLVI, 2006, p. 234-257.

PROENÇA Jr., D.; MUNIZ, J.; PONCIONI, P. “De la Gobernanza de Policía a la Governanza Policial". Gobernanza y Gestión de la Policía, vol. 1, p. 9-42. Caracas: Consejo General de Policía, 2011.

PUNCH, M. (ed.). Control in the Police Organization. The MIT Press, 1983.

QUIGLEY, C. Weapons Systems and Political Stability. University Press of America, 1983.

RADZINOWICZ, L. "That Strange Word Police". In A History of English Criminal Law and its Administration from 1750, vol 3, pp. 1-8. London: Sweet and Maxwell, 1956.

REITH, C. Blind Eye of History: A Study of the Origins of the Present Police Era. Patterson Smith, 1975.

REPPETO, T. A. American Police: A History, 1845-1945. Enigma Books, 2010.

RIGAKOS, G. S.; MCMULLAN, J. L.; JOHNSON, J. (Eds.). A General Police System: Political Economy and Security in the Age of Enlightenment. Red Quill Books, 2009.

ROCK, P. "Chronocentrism and British Criminology". The British Journal of Sociology, vol. LVI, n. 3, 2005, p. 473-493.

SAPORI, L. F. Sociologia: Política de segurança pública e controle da criminalidade - os desafios da provisão da ordem pública como bem coletivo. Tese de Doutorado, IUPERJ, 2006.

SARTORI, G. "Concept Misformation in Comparative Politics". The American Political Science Review, vol. LXIV, N. 4, 1970, p. 1033-1053.

SKOLNICK, J. Justice Without Trial: Law Enforcement in a Democratic Society, 2nd ed. New York: Wiley, 1975.

SILVA, E. M. A. Antropologia: Das reportagens policiais às coberturas de segurança pública: representações da "violência urbana" em um jornal do Rio de Janeiro. Tese de Doutorado, UFF, 2007.

SILVER, A. "1. The demand for order in civil society". In NEWBURN, T. (Ed.) Policing: Key Readings, Willan Publishing UK, 2006. 
SOARES, L. E. "A política nacional de segurança pública: histórico, dilemas e perspectivas". Estudos Avançados, vol. XXI, N. 61, 2007, p. 77-97.

STRECHER, V. G. "Revising the Histories and Futures of Policing". Police Forum, vol. I, N. 1, 1991, p. 1-9.

STYLES, J. "6. The emergence of the police". In NEWBURN, T. (ed.) Policing: Key Readings, p. 80-87. Willan Publishing (UK), 2006.

SUAREZ, G. The Tactical Advantage: A Definitive Study of Personal Small-Arms Tactics. Boulder: Paladin Press, 1998.

TEFERTILLER, C. Wyatt Earp: The Life Behind the Legend. Wiley, 1999.

UCHIDA, Craig D. "The Development of the American Police". In DUHAM, R.; ALPERT, G. (eds.) Critical Issues in Policing. Prospect Heights, Ill.: Waveland Press, 2001.

VICTOR, R. A. George Washington's Revolutionary Marshals. Infinity Publishing, 2004.

WADE, S. Square Mile Bobbies: The City of London Police 1829-1949. The History Press, 2008.

WADMAN, R. C.; Allison, W. T. To Protect and to Serve: A History of Police in America. Prentice Hall, 2003.

WALKER, S. The Police in America: An Introduction. New York: McGraw-Hill, 1992.

WALKER, S. "Science and Politics in Police Research: reflections on their tangled relationship". The Annals of the American Academy of Political and Social Science, vol. CXCIII, n. 1, 2004, p. 137-155.

WEBB, W. P. The Texas Rangers: A Century of Frontier Defense. University of Texas Press, 1965.

WILSON, J. Q. Varieties of Police Behavior: The Management of Law and Order in Eight Communities. Harvard University Press, Cambridge, MA, 1968.

ZALUAR, A. "Democratização inacabada: fracasso da segurança pública". Estudos Avançados, vol. XXI, N. 61, 2007, p. 31-49.

ZEDNER, L. "Policing before and after the police". The British Journal of Criminology, n. 46, 2006, p. 78-96. 